\title{
Editorial
}

\section{Restoration and Management as Theater}

There is a tendency for those involved in ecological restoration and management efforts to place themselves in the background and to make deliberate efforts to keep themselves and evidence of their work out of sight.

The famous "Leopold" report of 1963, for example, prescribes a program of scientifically based management for the national parks, but argues that this work should be kept out of view as far as possible.

To some extent, this posture is understandable. After all, restoration and management are the most self-effacing of all forms of agriculture. One of the most important-and to me attractive-things about this work is that it really is an exercise in placing oneself, along with one's ambitions to alter and fool around with the landscape according to one's tastes, firmly in the background.

At the same time, I think it is a mistake to let this selfabnegation with respect to the products of ecological management lead the manager to hide the extremely interesting, instructive-and I would even say inspiringmeans by which these ends are achieved.

In a word, what I want to say is that restoration and management have something to say-they mean and express something. And in fact this is one of their chief values-just as important as what we might think of as their purely ecological or environmental value.

A simple example will illustrate what I mean. Not long ago in a newspaper article about the spring burns here at the Arboretum, a local writer mentioned "the beautiful way Gene Moran (our crew foreman) burns the Arboretum's prairies."

That phrase captures the idea perfectly. Ecological management is not merely a technology, not just a job. As Frederick Turner points out in an article in this issue, it is an art. And more than that, it is a performing artliterally a form of theater.

This may seem a bit far fetched-a fanciful idea with little relevance to the real world or to the actual business of restoration and management. But I do not think that this is the case.

Think about it for a moment. As an ecologically oriented, practicing environmentalist, the manager's prime concern is not with objects as such or in isolation-that is, not with forests or prairies, or with populations of endangered species in and of themselves. It is with relationships-and, I would venture, especially with the relationship between our species and the rest of nature.

That is what ecology is all about, and it is an idea that is reinforced at every turn by sciences such as anthropology and sociology, which after all are really branches of ecology that happen to focus their attention on a single species.
Anthropology in particular emphasizes the importance of a culture's relationship with its environment, its ideas about this relationship, and the way it expresses these ideas. These, it turns out, are matters of final, vital importance. To a considerable extent, they define the culture. Ultimately, they are crucial to its survival.

This, then, is the critical question-not how can we save examples of the historic or prehistoric landscape but what sort of relationship are we going to have with that landscape?

And the answer, it seems to me, is defined by the whole business of ecological restoration and management.

What else is it-all the things the restorationist or manager does? Each operation-burning, flooding, or draining-each attempt to introduce a species or eliminate an exotic, all of these are acts of compensation for our presence. (At the higher, ethical level we might even say reparation, that word itself reflecting the ethical significance of the effort to "repair" what has been undone.)

What this adds up to, then, is a precise definition in ecological terms-not stated in words, but acted out, dramatized-of who we are and of our relationship to the system-that is, of our niche space.

For example: we here in the upper Midwest are the people who stopped the prairie fires (or eliminated the wolves), and who therefore now deliberately burn the prairies (or control populations of rabbits or deer) in acknowledgment of this.

It is in just this sense, I think, that the "natural" community proves a "benchmark" or reference point. It is not through watching the system, but through the active effort to restore or maintain it that we measure and evaluate our constantly changing relationship with it.

And it is essential to keep in mind that this relationship is not, finally, a personal matter. It is a social and cultural one-a population, not an individual matter. Hence the importance-especially in a democratic society-of letting everyone in on what is going on, of construing the work as a form of theater, and the parks, preserves, and wilderness areas as arenas in which it is carried on.

In the end, this is as important as the purely "ecological" value of the work, precisely because it $i$ part of the ecological value, we being, still, creatures and inhabitants of these systems. Its purpose is to heal, not only nature, but the bond with nature-and this is done by coming into contact, by clarifying, by educating, and finally by celebrating our life in nature.

Anything else-hiding the work, for example-is not theater, it is just pretending. It is playing house in nature. It is a step toward nature as Disneyland.

William R. Jordan III 